\title{
Using the Kano Model and the Quality of the Publishing Function in Evaluating Jordan's Academic Digital Libraries: A Case Study of the University of Jordan
}

\author{
Othman Abdulkader Obeidat* \\ Library and Information Management Department, Al-Salt College for Human Sciences, Al-Balqa Applied \\ University, Jordan, P.O. Box: Al-Salt 19117, Jordan \\ *E-mail: dr.othmanobeidat@bau.edu.jo
}

\begin{abstract}
This study is based on the evaluation of digital libraries of government universities in Jordan and it followed the descriptive and analytical approach based on the Kano model in assessing the requirements for the integration of digital libraries, which is called the "Home Model". The University of Jordan library was used as a case study and then circulated to other public universities for optimal use of digital libraries. A combination of two global models was used to set the Quality Function Deployment criteria. The Kano model as a useful tool for evaluating the quality of services provided by institutions without any consideration for their type. Data was collected to feed the quality of the publishing job-Kanoo model through a questionnaire that was distributed to a sample of users at the University of Jordan to assess the extent to which the services required from the digital libraries were achieved. Because this type of studies relies on listening to the voice of the user (Voice of User), which is the main goal and goal in providing services by institutions, especially libraries, and through this, valuable and relevant information on issues that should be improved In order to increase the users' satisfaction and complementarity in meeting their needs.
\end{abstract}

DOI: $10.7176 / \mathrm{IKM} / 10-4-01$

Publication date:May $31^{\text {st }} 2020$

\section{Introduction}

"It is impossible to have complete education systems without a suitable and strong system at the level of higher education, and to have centers of excellence, learning and training, and advanced library services. As moving forward on the issue of overcoming poverty and development in developing countries requires the key, which is higher education, and its heart, the academic libraries, and not just focusing on the technology side, but the need to focus on creating content and people who have enough knowledge to be able to use it. "(Holm-Nielsen, 2001). The revolution of digital information and communication technologies that the world is witnessing today has put more pressure on the role of libraries in general and academia, particularly, to transform their operations and provide their services digitally. This revolution, with the beginning of the twenty-first century, resulted in the emergence of the concept of the digital divide, which aims to shift from the traditional form in terms of service provision, adequate performance, accuracy and reduce the time and cost required to carry out scientific research at the level of higher education, with the aim of reaching a high degree of satisfaction with service users without the need for personal existence, other than what is required by it. Hence, the role that libraries should play is greater than any other institution in the field of computing and the use of digital technologies. As academic libraries began in advanced countries early in providing digital services.

Academic libraries services are developing their systems by facilitating access to information that enables them to carry out their daily work, writing research and increasing scientific production that improves the work environment in all areas of the country. For example, developed countries across the world choose different and advanced models with integrated infrastructures to provide their electronic and digital services, where these models may include: a portal to provide services available from academic institutions, or a full link to the interface to provide services with information systems for the academic bodies that provide them, Or a unified structure (as it is in the Center of Excellence in Jordan / Yarmouk University) for the channels of providing electronic services. We can say that the Hashemite Kingdom of Jordan has entered into the information society through the application of the unified index program through the Center of Excellence and the union of a group of universities in providing their services and digital resources that stems from the national plan for information technology, which includes providing communications and information technology services to all segments of the users. As the academic sector in cooperation with communications and information technology becomes a major source of development and overcoming the divide that separates us from developed countries. As digital libraries play a large and important role in reducing the digital divide. This role is as follows:

- Digital libraries, especially at the academic level, play the role of "Savior" for those who do not have access to scientific information and the impact of this divide on their well-being and the development of scientific research in a higher education environment. 
- The roles and efforts of academic digital libraries in bridging the digital divide and its impact on scientific research, which are still unknown and have not been discussed in most Arab countries.

- The results of this study can assist academic libraries and decision makers in making decisions to manage the open availability of digital information and then bridge the digital divide and develop scientific research between developed and developing countries.

\section{Objectives of the Study}

The purpose of the design of this study and the model used to evaluate the academic digital libraries in Jordan is to answer the following study question:

What role does the design of library sites and the digital information they contain play in helping Jordanian universities develop quality education, scientific research services and bridge the digital divide?

In order to help devise research methods that can provide relevant data to answer the research question, the following objectives have been identified:

1- Evaluating the role of digital libraries in Jordanian universities in overcoming the digital divide and its impact on scientific research.

2- The extent of setting and developing sites for academic libraries and setting up special training programs for information professionals and users.

\section{The Importance of the Study}

The results of this research help decision-makers, librarians, and academics to get to know the role of the digital library in bridging the digital divide and its role in developing scientific research, planning more for training programs, and providing Arab and international databases. In addition to the theoretical framework that will assist in conducting relevant research in the future. In addition to its importance in:

1- Developing the strengths and capabilities of digital libraries to provide scientific and digital contents to users.

2- Establishing the necessary infrastructure for information technology that helps support scientific research.

\section{Methodology of the Study}

To assess the satisfaction of the users, the primary goal of any institution should be service and the development of high-quality services. An appropriate method must be found to measure job procedures and processes. Therefore, the study used the SERVQUAL questionnaire tool to measure the quality of information provided by the University of Jordan Library in providing its services to users by distributing (270) questionnaires to the library users. (203) questionnaires were analyzed, which contained (25) variables, so that they are directly applicable to the digital library.

It was formulated to measure five dimensions of digital libraries through also relying on the Kano model and the quality of the publishing function, which was used in several scientific research to measure quality in providing services to institutions, and these dimensions are: (tangible materialism, components and elements, credibility and reliability, the ability to answer, and security). It should be noted that the questionnaire (SERVQUAL) does not consider the major issues of digital libraries, such as search engines, site search and link maintenance. It should be noted that the questionnaire (SERVQUAL) does not consider the major issues of digital libraries, such as search engines, site search and link maintenance. Therefore, it was necessary to design a specialized questionnaire for measuring quality in digital libraries for this study, and to reach this goal, a series of research was reviewed to develop a questionnaire for this study.

One of the studies reviewed for designing this questionnaire is the Mexican Library Association's study that focused on assessing information retrieval from the point of view of users and the extent to which they meet their needs (Behnert \& Lewandowski, 2017). Then Beck study (2005), which focused on some important features and characteristics of digital libraries such as: reliability of retrieved information, citation, integrity and objectivity, site maintenance, and the extent of coverage of available information. Other important features are the extent and size of information, website design and ease of use. Also, important studies are Lopez's proposed new evaluation criteria such as external perception of the digital form of publications, content and research on the site (Heradio etal, 2012).

After analyzing the studies mentioned above, the questionnaire was formulated by setting a set of features for digital libraries that were divided into four categories: information about users, site design and availability of information, site content and includes: (extent of coverage, form and quality of content), and evaluation of the private website at the library. A set of questionnaires was distributed to several users and employees of Al-Balqa University Library to know the existing errors and incomprehensible questions of the users. Their answers and comments helped to refine the questionnaire information and modify it to suit Jordanian and Arab academic libraries. The results of this research were used to apply it to the Kano and Deployment Quality Function model. 


\section{Problem Statement}

Due to the importance of the users' dealing with university libraries, it has consistently provided its services to users and workers in an advanced manner that keeps pace with modern technological developments, whether in the field of libraries, or in the field of supporting technologies for these libraries and other fields, where libraries have started to implement computerized systems to facilitate the work and procedures of the library.

The side of the employees and the users of the libraries represents an important element towards the success of the application of digital systems in the library through its services and sources of information to the final user, governmental or private institutions at the state level. University libraries must be dynamic, as they must interact with the surrounding environment and be affected by everything that begins and happens with them.

\section{Hypotheses}

Based on the previous methodology, the following hypotheses can be formulated:

The First Hypothesis

The Nihilistic Hypothesis: The design of the site and the search engines in the digital library at the University of Jordan does not achieve the proper acquisition of information services.

The Alternative Hypothesis: Site design and search engines in the digital library at the University of Jordan achieve access to information services as appropriate.

The Second Hypothesis

The Nihilistic Hypothesis: The contents of the digital library at the University of Jordan do not meet the needs and full satisfaction of the users.

The Alternative Hypothesis: The contents of the digital library at the University of Jordan meet the needs and full satisfaction of the users.

\section{Literature Review}

The storage of information, advanced retrieval systems and search engines is now on the Internet, making remote access to large amounts of information easy and possible. For example, these capabilities develop business, educational, and private life, whether at work or home.

The fourth information revolution usually refers to the processing of large amounts of information. The first event appeared with the invention of the alphabet (1400 BC), and the second with the practice of handwriting in China (1300 BC), However, the most important change in the information world was documented with the invention of the printing press by Gutenberg in 1451. Prior to Gutenberg there were only about 30,000 books in all of Europe; but before the year 1500 this number reached 9 million with the invention of the printing press (Briggs \& Burke, 2002). In the modern era, networked computers have had a similar impact on society, and a significant change in the amount of information we can access in the realm of our world. It represents the fourth information revolution (Cochran etal, 2000; van den Hoven et al, 2019; Druker, 1999; Gates, 1995; Schwab, 2016).

As the backbone of Internet search engines, the Internet has played a crucial role in developing digital information sources and making major changes in academic libraries in terms of access and storage for large groups. On this basis, the process of transition from traditional methods to digital libraries is unavoidable and consideration should be given to developing a clearly defined framework for an evaluation to which voice of users (VoU) should be an issue of interest (Eke; Omekwu; and Agbo, 2014). This study proposes a combination of Quality of Posting Function (QFD) and Kano Model as a useful tool to assess the quality of service. The University of Jordan Library is presented as a case study, and the study focused on issues related to quality of service in terms of digital library requirements.

Academic libraries are in constant change, so they must adapt to this change in order to be able to understand the needs of society in addition to continuity. Over the past thirty years, academic libraries have made a lot of efforts to change the way information is collected, classified, and converted into electronic catalogs, databases, and electronic books and make it available on the internet. Governments, including universities and industries, are working hard to implement and apply new information technologies within academic and public libraries and encourage a change from the traditional to the digital libraries (MacCall, 2006; Saarti, 2006, Zhou, 2005).

The digital library is not actually a library in terms of the physical and tangible location; rather, it is a virtual site with digital information sources and multimedia. Rather, it is built through digitizing information, such as documents, videos and audio recordings, while achieving the goal of providing information services to users quickly and easily via the Internet 24/7/360, as well as sharing available resources (Wang, 2003; Office of Educational Technology, 2017).

\subsection{Benefits of digital libraries}

The vast storage capacity of information and resources in various media across the internet, information sources, distributed information resource management, shared information resources, smart retrieval technology, and information services provided without space and time constraints (Zhou, 2005). And digital libraries cover a wide 
range of topics in specialized databases where access to information stored on the Internet no longer requires users to visit buildings and sites. Whereas, remote access to digital libraries restores digital resources from around the world as quickly as possible (Sharma and Vishwanathan, 2001; Tonta, 2004), because there are interactions with digital libraries and large amounts of diverse information.

There is a need for sound management policies to ensure user satisfaction and should include proposals to ensure quality of service through continuous evaluation plans. These plans should also focus on the voice of the user $(\mathrm{VoU})$, through local questionnaires related to the institution, through which relevant information can be collected in order to ensure the development of digital libraries according to the needs of the users. However, assessing the quality of digital libraries is more complicated by using questionnaires. Although the purpose is to find strengths and weaknesses in digital libraries that aim to make improvements and developments that meet the needs of users, the quality assessment should also be based on sound quality incorporating the philosophy based on the main actors of the users (Abdullah, 2006).

Quality management activities require the creation of metrics or indicators to know the extent to which the quality goals are achieved and thus how much the needs of the users are met (International Labor Organization, 2012; Abdullah, 2009). The common problem in any evaluation of traditional or digital libraries is to measure their performance by numbers, as the first rule in performance evaluation is on a number of books in circulation and the number of users, books purchased, and the second rule on evaluation that includes the use of accessibility, and in terms of existing functionality, as well as the reference service or online help (Houghton, 2004). However, both approaches used were not related to the evaluation issues for the satisfaction of the users.

In the field of digital library evaluation, there are some studies that have considered the expectations and needs of the users. Colin examined the relationship between the quality of the service provided and the satisfaction of the users by measuring the gap in the available services or services provided by libraries In addition to analyzing how to measure the use of electronic content and services provided by academic libraries, analyzing opinions and expectations and how users benefit from digital services, and some of them called for monitoring the users' behavior and evaluating them in the context of digital content, and some of them see that satisfaction of the users can be achieved through the distribution of a questionnaire on users. A survey was conducted to collect the suggestions of the users and to arrange these suggestions in groups according to the characteristics of the suggestions submitted by the users. (Kani Zabihi et al, 2006; Cullen, 2001; Breeding, 2002; Xia, 2003; Banwell et al, 2004; Schryer, 2006).

It is clear from these studies that there are not always clear ways to listen to the voice of the user VoU, which includes the appropriate technical requirements for the digital library. Thus, it is not only important to take what is in the voice of the user VoU, it is also necessary to translate that into appropriate actions on the ground. In this context, the aim of this study is to assess the satisfaction of users of a digital library with an emphasis on the user's voice, using the QFD methodology and the Kano model to translate the user's voice into technical requirements.

\subsection{Quality Deployment Function Model (QFD)}

The Quality Deployment Function Model is a structured method for translating users' requirements into appropriate technical requirements for each stage of service and product development. The QFD process is often referred to as listening to the voice of a customer in management, commerce, and the user in libraries. This process was applied for the first time in Mitsubishi in 1972, and later in 1980 it was introduced in the United States and since then this model is used to develop services and improve the quality of performance all over the world, whether in the field of services or manufacturing and trade operations (Uppalanchi, 2010; Abdullah, 2009). And the search in the specialized references in the index of science and quotation from the Institute of Scientific Information (ISI) from 2005 to 2009, has indicated the production of 49 records containing the phrase quality of the deployment function in its titles and 170 words as if it was a topic presented on the quality of the deployment function and discussed some records in Specific Qapplications and other improvements. The ultimate benefits of the deployment function quality model applications have been reported, which are that they are lower than product development costs and increase customer or user satisfaction and market share (International Labor Organization, 2012).

The Quality Deployment Function Model uses a series of matrices to express the connections between inputs (what is it and how it is? Users' requirements) and outputs in terms of (how to meet technical needs and requirements) at different stages of development. The first matrix known as the Quality House is the only model applied in this paper, and it appears in Figure 1, and building a Quality House model requires six stages as will be explained in the following example:

The library user community consists of three members to benefit from the services of the digital library:

- the students,

- faculty members, and

- Members of the administrative body. 


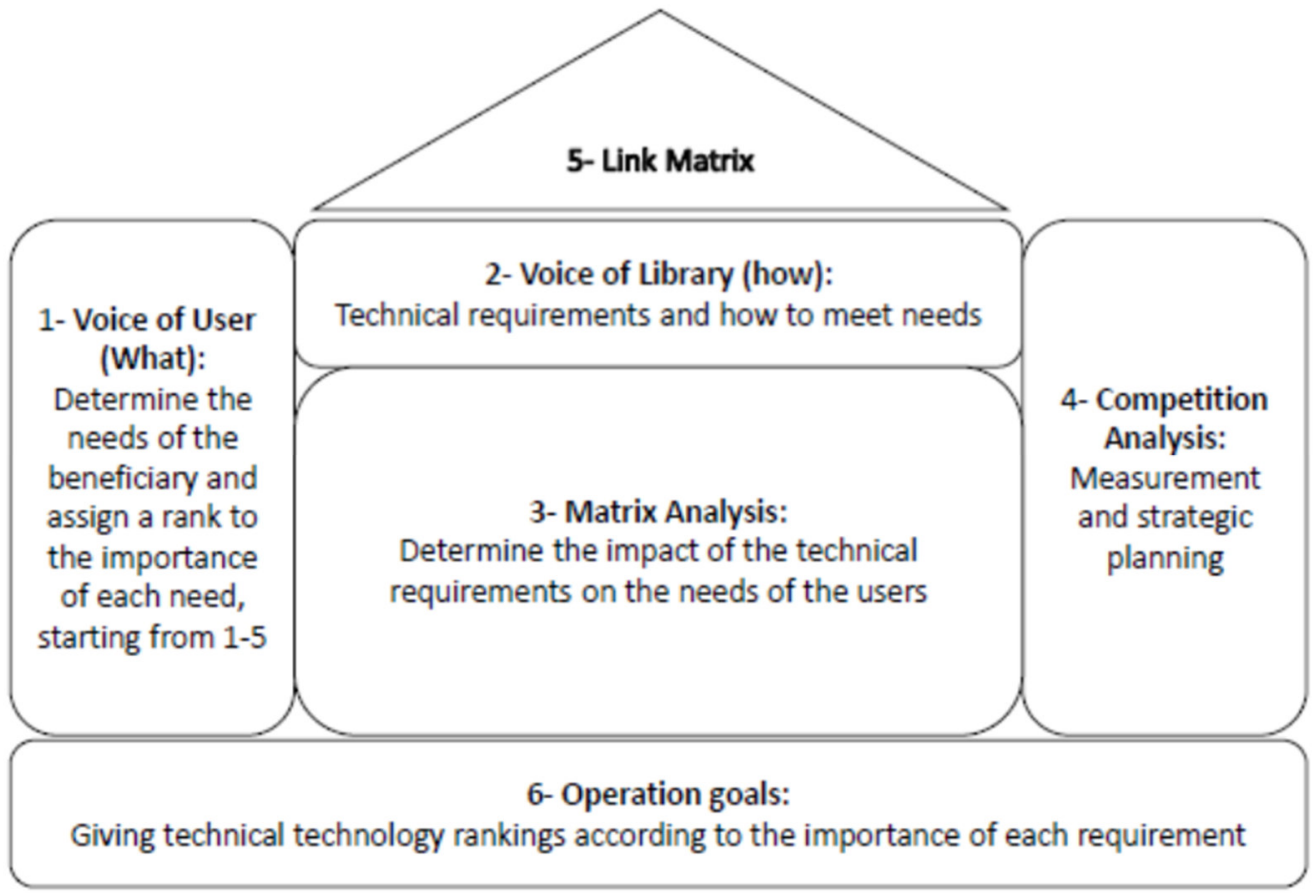

\subsubsection{Link Matrix}

Figure (1): Framework for Quality Deployment Function Model

\section{Objectives of the Operation}

Provide ranks for the technical requirements according to the importance of each requirement

The First Stage: The Users 'Requirements ... (The Users' Voice ... What?)

One of the objectives of the Quality Deployment Function Model is to ensure that all the requirements of the users are met, and therefore it is necessary to identify the users, and in the academic community: students, teachers and administrators are the users of the processes (i.e. those who benefit from the digital library). Each member has specific requirements, for example, students prefer using the library anywhere they are and avoid the distance. As for the teachers, their requirements are that they have the latest publications in their fields of specialization, and the requirements of administrators in how to meet the needs of teachers and students alike despite all the requirements of the users, and it is necessary to set priorities for them based on their impact on the satisfaction of the users in general. It is a good practice to rate the expectations of all library users with a scale of 1-5 with 1 being the least important and 5 being the most important. Also, for example, Figure 2 illustrates the importance of what is?

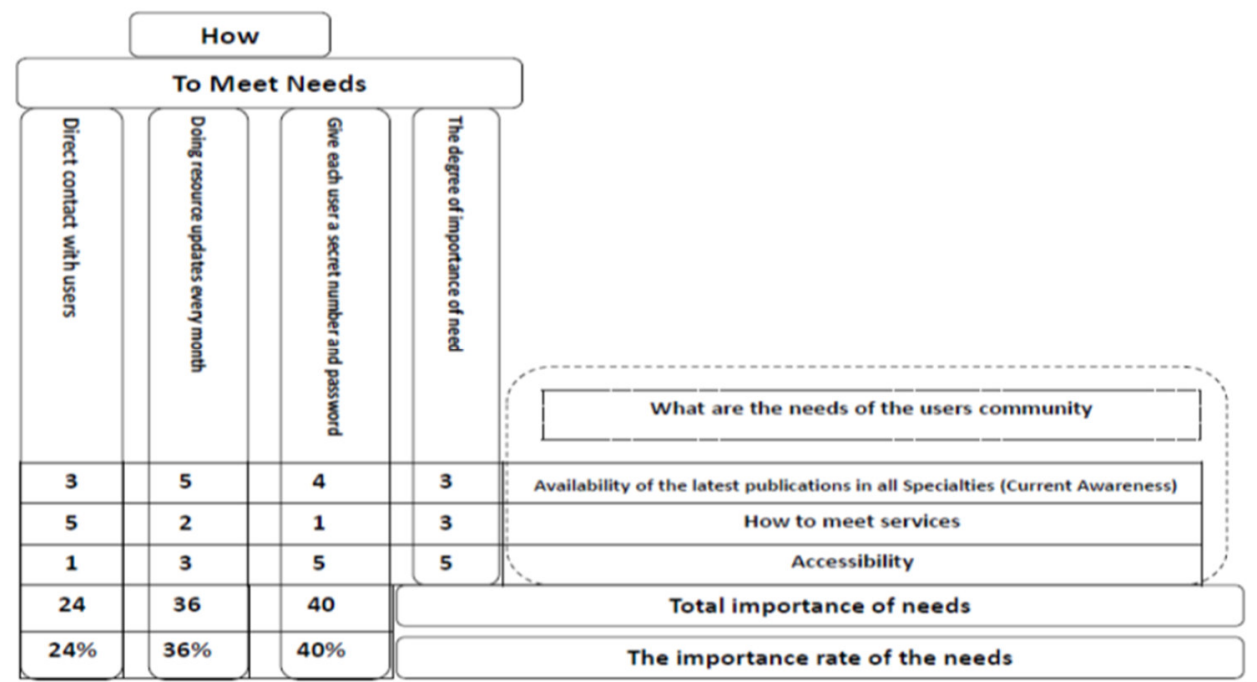

Figure (2) planning matrix to meet the needs

The second stage: technical requirements (how can)

After determining what the requirements are "What", it is necessary to answer the question "How" can the process 
of accessing the resources be easy, providing the latest versions, and satisfying all services equally? In other words, what are the steps / procedures necessary to ensure that all needs are met and the proposed alternatives to answer "what" can be found in a list that represents technical requirements, for example:

The answer to the question "How" to meet the services of users by listening to the voice of the users that the library must take into account in its location or by allocating a corner of the library's website in particular to provide suggestions to the users and work to meet them at the lowest costs and by the best way, and in the same path to complete all the requirements, as shown in Figure 2.

The Third Stage: Matrix Relationship

Since "what" and "how" may not be independent, and how it can affect more than what, it is necessary to assess the relationship between "what" and "how". The main question is: How far "How" achieves "what"? Since the need and how to meet it are related to each other, it is necessary to evaluate the relationship between them and relations are usually defined as follows:

$5=$ strong relationship

$3=$ Moderate Relationship

$1=$ Weak relationship

$0=$ No relationship

Fourth stage: Competition Analysis

The requirements of libraries users are studied through methodologies such as measurement and strategic planning as in Figure 5, and matrix planning.

Fifth Stage: Correlation Matrix

It is sometimes called a "roof" of a quality house, and it provides a way to capture information about how to meet the needs that may interact with each other, either in a positive or negative way. For example, the process of continuous updating is associated with direct contact positively, because when the user contacts the library and determines his need, the search will be done quickly to meet those needs. This means that the cost of using digital libraries will be high, knowing that the study sample library uses databases, electronic resources and activities for users, which shows a positive relationship. This means that the cost will rise when wanting to increase the use of digital libraries and an increase in unwanted costs, that is, they are negatively related, and for this reason a double link ("- -") was indicated and placed at the intersection between the two columns. It is suggested that two of them, how strongly related in a negative way. The links are an early warning of how that sometimes may not be practical. It may not be possible to use all resources in digital libraries and the subscription cost remains high.

The Sixth Stage: The Objectives of the Process

This stage involves calculating the importance of how to meet the need (technical requirements) based on its effect on the requirement "what" can. At this stage the importance of the need that appears in the last rows in the table as in Figure (2) is calculated through the following equation:

Importance of need $=\sum$ (degree of need importance $*$ degree of need itself)

The importance of need ratio $=($ degree of importance of need $/$ total importance of need $) * 100 \%$

For example, the importance of the need for continuous updates can be calculated from

$(5 * 3)+(3 * 2)+(5 * 3)=36$

As for the importance of the need to carry out modernization operations, it is as follows:

First: the importance of need is 36

The total importance of needs is 100

Second: Applying the equation: $(36 / 100) * 100 \%=36 \%$

The application is also applied to the rest of the needs.

\section{The Kano Model}

Kano et al. Developed a model for classifying service attributes based on their ability to meet the needs of users (Kano et al, 1984). It relates to the relationships between user satisfaction and service performance. The Kano model identifies three different categories of how to understand the needs of users in order to achieve satisfaction (Matzler and Hinterhuber, 1998). 


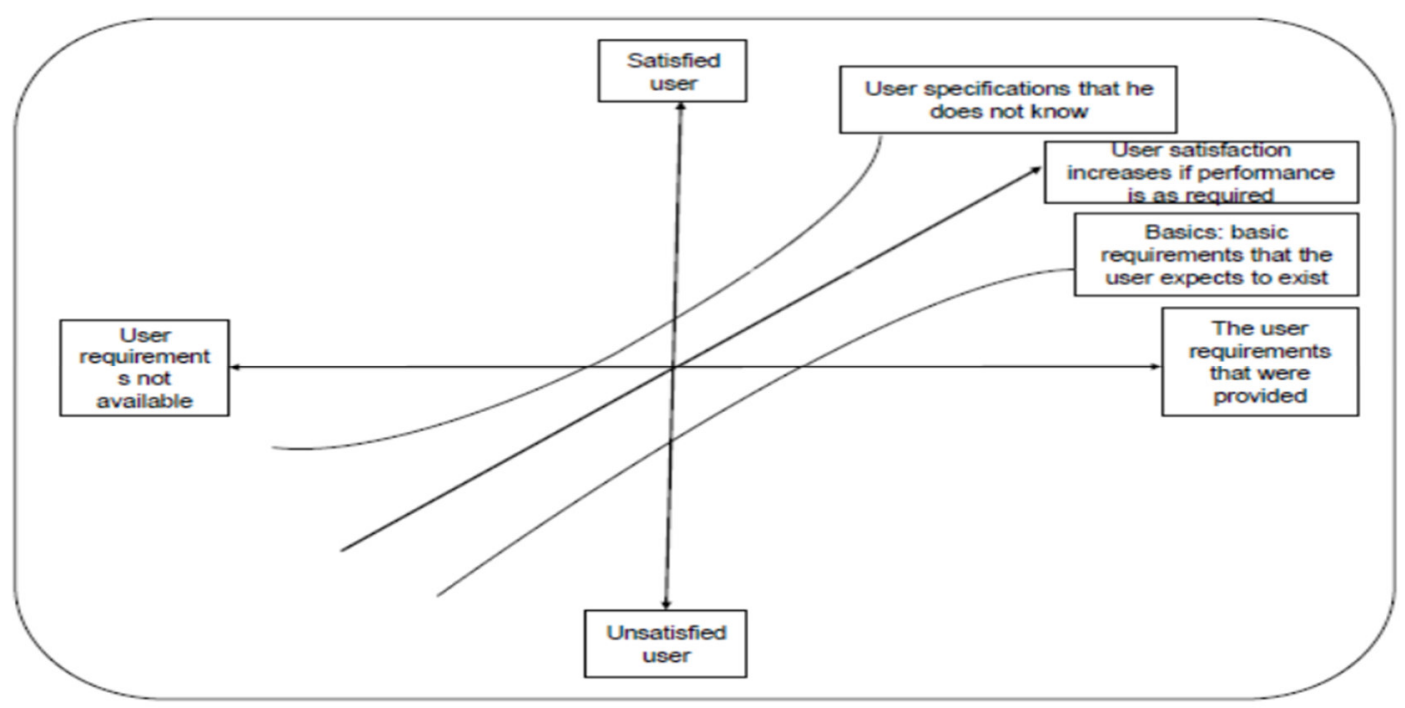

Figure No. (3) Kano model

\subsection{Attractive features (needs that attract the users)}

The lack of it does not cause resentment because it depends on the expectations of the users, so many users do not realize what are the things they lose, however these features must be achieved in order to achieve the satisfaction, which increases in parallel with the performance of the feature.

\subsection{Essential features (the basic needs that must be met for users)}

It is the attribute that the user takes for granted. However, if the service does not satisfy the basic needs sufficiently, the user will become very dissatisfied. Additionally, the Kano model assumed that those characteristics which were deemed attractive could decrease over time and become one dimension. Attractive fellowship features may take over time and fall into the only meeting category for the primary needs of the users. Therefore, the timely and continuous development of the library is important, as is the introduction of new services.

\subsection{Hybridization of the Quality Deployment Function Model and the Kano Model}

The critical step in implementing the Quality Deployment Function model is to identify users' requirements and set their priorities. The priorities should reflect what the users want most. Therefore, it is necessary to obtain true information about the satisfaction of the users and to provide enough analysis in order to properly prioritize in order to satisfy their desires. In this context, the Kano model provides an effective approach to the priorities of users' requirements and helps to understand the nature of each of them (Matzler and Hinterhuber, 1998). The combination of the Quality Deployment Function Model and the Kano Model is a hybrid methodology suitable for listening and better understanding the requirements of the user community. A major issue in this approach is how the needs of the users are prioritized in the Quality Deployment Function Model by the Kano model. Tan and Pawitra (2001; Priyono \& Yulita, 2017) suggested that attractive traits should receive attention first, then performance traits, and finally basic traits and the main disadvantage of this methodology is the lack of knowledge of which basic traits have the lowest performance and due to which The users will be very dissatisfied, as shown in Figure 3.

Better results can be obtained if the prerequisite features are given a higher priority. On this proposed basis, the two studies (Tan and Shen, 2000; Priyono \& Yulita, 2017) indicated the re-prioritization of all requirements of clients or users as a (feature) by the Quality Deployment Function Model, and analyzing the improvement rate using the following formula:

IRadj $=($ IR0) $1 / \mathrm{k}$

whereas:

IRadj $=$ is the job improvement rate

IR $0=$ is the original improvement percentage

$\mathrm{K}=$ is the Kano coefficient of three different features

IR0 can be calculated from the following equation:

$\mathrm{S} 1 / \mathrm{S} 0$

whereas:

$\mathrm{S} 1=$ target user satisfaction (planned level)

$\mathrm{S} 0=$ current user satisfaction level 
Users' attributes can be categorized within Kano's known ratings, for example Performance requirements $=1$, attractive features $=2$, basic features $=0.5$

Once users' attributes can be categorized into the appropriate Kano categories, as shown in Figure No. (3), in return, $(\mathrm{K})$ can be chosen. For example, a set of possible values of $(\mathrm{K})$ includes " 1 " for a one-dimensional attribute, " 2 " for the attribute to be attractive and " 0.5 " for the attribute should be, respectively.

Figure 4 shows the original improvement ratio (IR0) with respect to the improvement of the control parameter (IRadj) for several values of $\mathrm{K}$. It can be seen as a ratio of (IR0 $>1$ ), and the performance of the interview process is poor, because $(\mathrm{S} 1<\mathrm{S} 0)$. In other words, bad processes that occur at the current level of user satisfaction (S0) are lower than the target level of user satisfaction (S1). On this basis, the basic features should be met first, followed by the necessary needs, and then the attractive features.
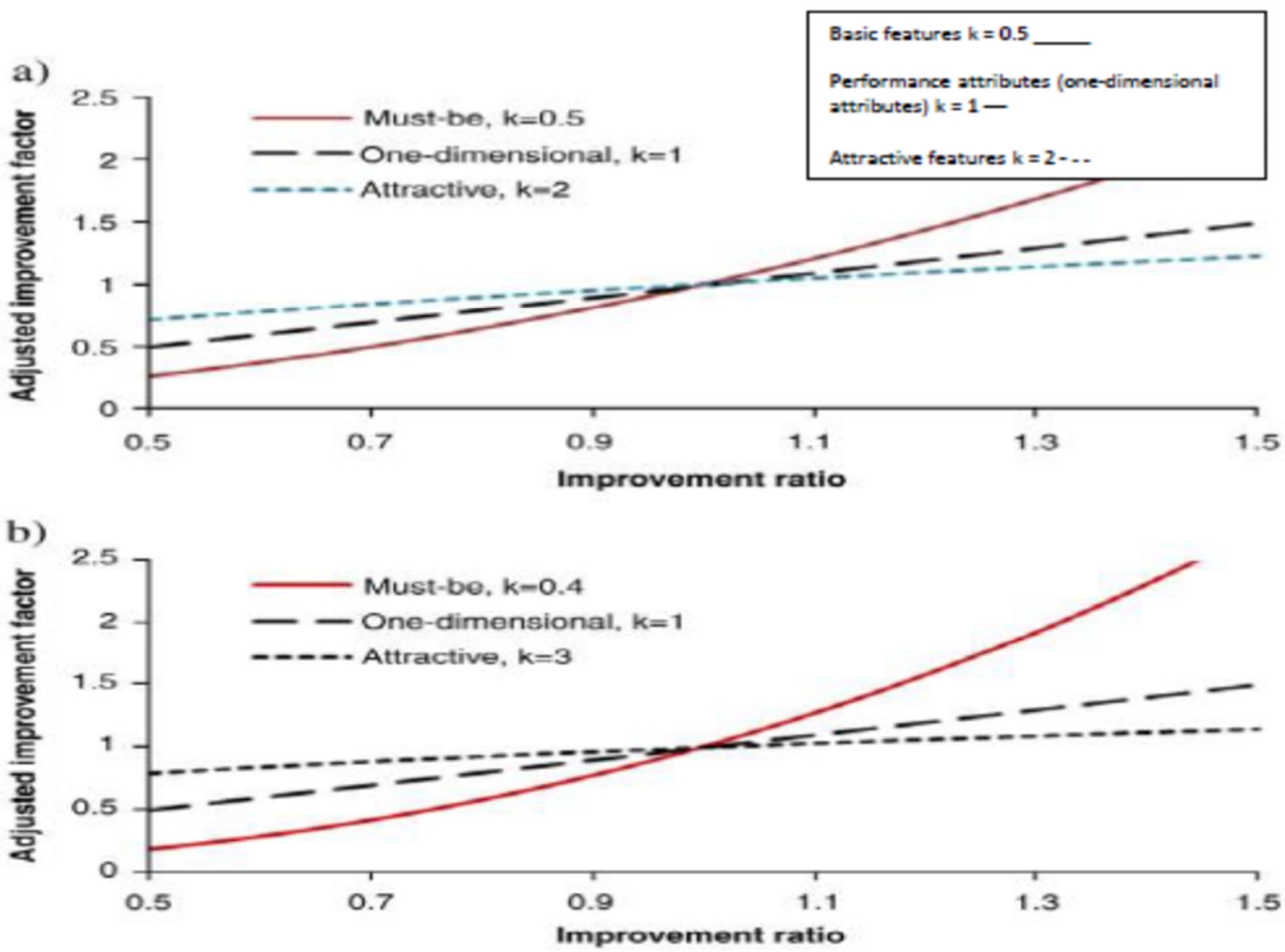

Figure (4) the original improvement ratio (IR0) with respect to the improvement of the control parameter (IRadj) for several $\mathrm{K}$ values.

\section{Analysis and Discussion of the Results of the Questionnaire}

The study population included all the users of the University of Jordan Library of various levels of study, Bachelor, Master, Doctorate, and staff. The study sample also included 203 library users who use the university's digital library website. Mathematical iterations were used to find the personal information of the individuals in the study sample. Also, the Alpha Cronbach test was used to know the validity of the study tool, as well as the arithmetic mean, standard deviations and (t-test) to test the study hypotheses. In order to measure the validity of the study tool, the Alpha Cronbach test was used, and the test result was equivalent to $(0.85 \%)$. This is a high value and indicates that there is validity of the study tool that enables researchers to take a test of the study hypotheses as appropriate.

\subsection{Analysis and discussion}

The results of the above analysis showed that there are 44 members of the study sample who are from the Faculty of Educational Sciences, and the lowest percentage was one individual from the College of Education and Arts $(0.5 \%)$. Also, there are 10 individuals from the Faculty of Information Technology and 23 individuals from the College of Engineering. 
Table No. (1) Distribution of colleges to which the study sample belongs

\begin{tabular}{|l|c|c|}
\hline \multicolumn{1}{|c|}{ Variable } & Repetition & Percentage \\
\hline Educational and Social sciences & $\mathbf{4 4}$ & $\mathbf{2 1 . 7}$ \\
\hline Education and the Arts & $\mathbf{1}$ & $\mathbf{0 . 5}$ \\
\hline Information Technology & $\mathbf{1 0}$ & $\mathbf{4 . 9}$ \\
\hline Engineering & $\mathbf{2 3}$ & $\mathbf{1 1 . 3}$ \\
\hline Business & $\mathbf{1 2}$ & $\mathbf{5 . 9}$ \\
\hline Other than that, $\quad \mathbf{1 1 3}$ & $\mathbf{5 5 . 7}$ \\
\hline \multicolumn{1}{|c|}{$\quad \mathbf{2 0 3}$} & $\mathbf{1 0 0 \%}$ \\
\hline
\end{tabular}

There are 12 individuals from the College of Business, as well as the highest percentage of those who answered the questionnaire were 113 individuals (55.7\%) classified other than the departments mentioned in the questionnaire, which may include some employees and other departments at the university who use the library and its website.

\begin{tabular}{|c|c|c|}
\hline Variable & Repetition & Percentage \\
\hline Academic & 20 & 9.9 \\
\hline Library employee & 24 & 11.8 \\
\hline Student & 159 & 78.3 \\
\hline Total & 203 & $100 \%$ \\
\hline
\end{tabular}

The results of the analysis indicate that there are only $20(9.9 \%)$ of the individuals who answered the questionnaire are in an academic position, and there are 24 library staff with an administrative position and the highest percentage constitutes $159(78.3 \%)$ of students, and this indicates that most of the questionnaires were directed to students and this is what It strengthens this study because students are the most connected groups of users with digital libraries.

Table No. (3) Internet usage period

\begin{tabular}{|l|c|c|}
\hline \multicolumn{1}{|c|}{ Variable } & Repetition & Percentage \\
\hline less than one year & $\mathbf{2 5}$ & $\mathbf{1 2 . 3}$ \\
\hline Between 1-3 & $\mathbf{5 6}$ & $\mathbf{2 7 . 6}$ \\
\hline Between 4-6 & $\mathbf{4 8}$ & $\mathbf{2 3 . 6}$ \\
\hline More than 6 years Total & $\mathbf{7 4}$ & $\mathbf{3 6 . 5}$ \\
\hline \multicolumn{2}{c}{ To3 } & $\mathbf{1 0 0 \%}$ \\
\hline
\end{tabular}

As for the periods of use of the Internet by the users, the data above indicate that the lowest percentage was 25 individuals (12.3\%) using the Internet during less than a year only, and this indicates that a large percentage of the academic community has a high ability to use digital information sources both on the Internet or in the university library. There are (27.6\%), i.e. 56 members of the sample who answered the questionnaire, their use of the Internet was between one to three years, and there are 48 individuals who indicated that their use of the Internet is between four to six years, and the highest percentage of users and members of the sample is $74(36.5 \%)$ of out of 203 people who have been using the internet for more than 6 years, this indicates that the majority of the study sample has been using the Internet for research for a long time, and this is a great indication that the sample members have the basic skills through which they can benefit from the sources of digital libraries.

Table No. (6) Number of visits to the library's website

\begin{tabular}{|l|c|c|}
\hline \multicolumn{1}{|c|}{ Variable } & Repetition & Percentage \\
\hline Once a month & $\mathbf{2 2}$ & $\mathbf{1 0 . 8}$ \\
\hline Twice a month & $\mathbf{4 3}$ & $\mathbf{2 1 . 2}$ \\
\hline 3 times a month or less & $\mathbf{3 9}$ & $\mathbf{1 9 . 2}$ \\
\hline More than 5 times a month & $\mathbf{9 9}$ & $\mathbf{4 8 . 8}$ \\
\hline \multicolumn{1}{|c|}{ Total } & $\mathbf{2 0 3}$ & $\mathbf{1 0 0 \%}$ \\
\hline
\end{tabular}

The above data indicates that there are 39 individuals from the study sample who arrive at the library more than 3 times a month and that there are 22 individuals who visit the library once a month. Likewise, there are 43 members of the study sample who visit the library's website 3 times a month, as well as the highest percentage (99 $(48.8 \%))$ of the study sample who visit the library four times a month or less. This is further evidence that the users are highly dependent on the use of digital resources. 
Table No. (7) the type of resources used in the Internet

\begin{tabular}{|l|c|c|}
\hline \multicolumn{1}{|c|}{ Variable } & Repetition & Percentage \\
\hline Full text of databases & $\mathbf{3 0}$ & $\mathbf{1 4 . 8}$ \\
\hline Publishers' catalogs & $\mathbf{4}$ & $\mathbf{2 . 0}$ \\
\hline Magazines and e-books & $\mathbf{4 5}$ & $\mathbf{2 2 . 2}$ \\
\hline Sites of interest & $\mathbf{1 2 4}$ & $\mathbf{6 1 . 1}$ \\
\hline \multicolumn{1}{|c|}{ Total } & $\mathbf{2 0 3}$ & $\mathbf{1 0 0 \%}$ \\
\hline
\end{tabular}

The results of the above analysis showed that the least 4 (2.0\%) of the sample individuals only use publishers 'catalogs, and this indicates that academics in Jordanian universities do not have access to how to use the Internet and the databases provided by the library to obtain publishers' catalogs. The results indicated that there is only (14.8\%) of the 203 sample respondents who go to use the "full text of databases" and there are 45 members of the study sample who go to benefit from "magazines and electronic books". Finally, the results indicate that 124 $(61.1 \%)$ of the study sample members, which is the highest percentage, who use sites of importance and relevance to their studies and research and the academic environment, that is, they rely on more rapid information than rely on tight academic articles that universities participate in.

Table No. (8) Services provided by the Digital Library at the University of Jordan.

\begin{tabular}{|l|c|c|}
\hline \multicolumn{1}{|c|}{ Variable } & Repetition & Percentage \\
\hline Index & $\mathbf{8 0}$ & $\mathbf{3 9 . 4}$ \\
\hline Electronic sources & $\mathbf{4 8}$ & $\mathbf{2 3 . 6}$ \\
\hline Reference works & $\mathbf{1 1}$ & $\mathbf{5 . 4}$ \\
\hline Online reservation & $\mathbf{1 1}$ & $\mathbf{5 . 4}$ \\
\hline Electronic books & $\mathbf{4 4}$ & $\mathbf{2 1 . 7}$ \\
\hline Full-text databases & $\mathbf{9}$ & $\mathbf{4 . 4}$ \\
\hline \multicolumn{1}{|c|}{ Total } & $\mathbf{2 0 3}$ & $\mathbf{1 0 0 \%}$ \\
\hline
\end{tabular}

The results also showed in Table No. (9) that there are $62(30.5 \%)$ of the study sample individuals who are aware of the contents of electronic sources and that there are $111(54.7 \%)$ of the study sample individuals who are aware of some of them and also there are 30 (14.8\%) of the study sample members who are not aware of the library's contents from digital information sources, and this result calls on the library to pay more attention to training and marketing of its sources for use.

Table No. (9) the level of users' awareness of the contents of electronic sources

\begin{tabular}{|c|c|c|}
\hline Variable & Repetition & Percentage \\
\hline Aware & $\mathbf{6 2}$ & $\mathbf{3 0 . 5}$ \\
\hline Aware of some of them & $\mathbf{1 1 1}$ & $\mathbf{5 4 . 7}$ \\
\hline Not aware Total & $\mathbf{3 0}$ & $\mathbf{1 4 . 8}$ \\
\hline \multicolumn{2}{|c|}{ To3 } & $\mathbf{1 0 0 \%}$ \\
\hline
\end{tabular}

\subsection{Website design and use of search engines}

The design of the website for the digital library plays a big role in the development of the academic community and then overcoming the information gap that separates Arab countries from developed countries. Therefore, evaluation studies are needed to help Arab universities develop their websites and provide digital databases with their full texts to reach advanced stages that are equivalent to what is in the developed countries. In this part of the research, the results of the design of the Jordan University Library website and the extent of satisfaction of the users about it will be discussed. The results of the answer to the questionnaire regarding this axis indicated that "the ability to search for resources through the use of the library's website" was more than (70\%), which indicates that the users have a high degree of satisfaction with the ease and possibility of research and with a standard deviation of $(4,05)$. This result is supported by another result from the following question, "How does the Webpage home page describe the library on the university's website?", to which the users also responded with a high rate exceeding more than $(70 \%)$, which is an estimate between "good and very good", which was respectively deviating a similar standard for the first question that is estimated at (3.99). 
Table No. (10) Users' satisfaction with the design of the library's website

\begin{tabular}{|c|c|c|c|c|c|c|}
\hline Questions & $\begin{array}{l}\text { Very } \\
\text { Good }\end{array}$ & Good & Medium & Bad & $\begin{array}{l}\text { Very } \\
\text { Bad }\end{array}$ & $\begin{array}{l}\text { Standard } \\
\text { Deviation }\end{array}$ \\
\hline $\begin{array}{l}\text { 1. How would you rate the ability to search } \\
\text { for resources by using the library's website? }\end{array}$ & $\begin{array}{c}86 \\
42.4 \%\end{array}$ & $\begin{array}{c}62 \\
30.5 \%\end{array}$ & $\begin{array}{c}43 \\
21.2 \%\end{array}$ & $\begin{array}{c}5 \\
2.5 \%\end{array}$ & $\begin{array}{c}7 \\
3.4 \%\end{array}$ & 4,05 \\
\hline $\begin{array}{l}\text { 2. How do you describe the Webpage home } \\
\text { page for the library on the university's } \\
\text { website. }\end{array}$ & $\begin{array}{c}74 \\
36.5 \%\end{array}$ & $\begin{array}{c}75 \\
36.9 \%\end{array}$ & $\begin{array}{c}37 \\
18.2 \%\end{array}$ & $\begin{array}{c}13 \\
6.4 \%\end{array}$ & $\begin{array}{c}4 \\
2.0 \%\end{array}$ & 3.99 \\
\hline $\begin{array}{l}\text { 3. Extent of obtaining relevant information } \\
\text { through Links }\end{array}$ & $\begin{array}{c}49 \\
24.1 \%\end{array}$ & $\begin{array}{c}68 \\
33.5 \%\end{array}$ & $\begin{array}{c}64 \\
31.5 \% \\
\end{array}$ & $\begin{array}{c}17 \\
8.4 \%\end{array}$ & $\begin{array}{c}5 \\
2.5 \%\end{array}$ & 3.68 \\
\hline $\begin{array}{l}\text { 4. How would you rate the means to get } \\
\text { online help? }\end{array}$ & $\begin{array}{c}67 \\
33.0 \%\end{array}$ & $\begin{array}{c}61 \\
30.0 \%\end{array}$ & $\begin{array}{c}52 \\
25.6 \%\end{array}$ & $\begin{array}{c}17 \\
8.4 \%\end{array}$ & $\begin{array}{c}6 \\
3.0 \%\end{array}$ & 3.81 \\
\hline $\begin{array}{l}\text { 5. What do you think of the time spent } \\
\text { searching and finding the answer to the } \\
\text { information? }\end{array}$ & $\begin{array}{c}47 \\
23.2 \%\end{array}$ & $\begin{array}{c}70 \\
34.5 \%\end{array}$ & $\begin{array}{c}62 \\
30.5 \%\end{array}$ & $\begin{array}{c}17 \\
8.4 \%\end{array}$ & $\begin{array}{c}7 \\
3.4 \%\end{array}$ & 3.65 \\
\hline $\begin{array}{l}\text { 6. How do you look at the search engines on } \\
\text { the digital library website for different } \\
\text { sources? }\end{array}$ & $\begin{array}{c}42 \\
20.7 \%\end{array}$ & $\begin{array}{c}77 \\
37.9 \%\end{array}$ & $\begin{array}{c}52 \\
25.6 \%\end{array}$ & $\begin{array}{c}23 \\
11.3 \%\end{array}$ & $\begin{array}{c}9 \\
4.4 \%\end{array}$ & 3.59 \\
\hline $\begin{array}{l}\text { 7. What is your assessment of the support of } \\
\text { the use of the Internet at the University of } \\
\text { Jordan? }\end{array}$ & $\begin{array}{c}81 \\
39.3 \%\end{array}$ & $\begin{array}{c}51 \\
25.1 \%\end{array}$ & $\begin{array}{c}40 \\
19.7 \%\end{array}$ & $\begin{array}{c}21 \\
10.3 \%\end{array}$ & $\begin{array}{c}10 \\
4.9 \%\end{array}$ & 3.84 \\
\hline $\begin{array}{l}\text { 8. Do you feel that there is a weakness in } \\
\text { providing tools and facilities when using the } \\
\text { University Library website? }\end{array}$ & $\begin{array}{c}26 \\
12.8 \%\end{array}$ & $\begin{array}{c}61 \\
12.8 \%\end{array}$ & $\begin{array}{c}70 \\
34.5 \%\end{array}$ & $\begin{array}{c}26 \\
12.8 \%\end{array}$ & $\begin{array}{c}20 \\
9.9 \%\end{array}$ & 3.23 \\
\hline
\end{tabular}

The users from the library indicated that obtaining the relevant information through direct links, the results that indicated nearly half of the answers of the selected sample indicated that a number of those who answered the questionnaire indicated that the ratio is medium in relation to the question of direct linking to related articles to the original research at a rate of $(31.5 \%)$. The users from the library indicated regarding the question "means to get help on the Internet" was good by $(63 \%)$, and also the results of answering the question "the time taken to search and find the answer to information" was close to the previous question in terms of the proportion of approximately half $(57.7 \%)$ were between "good and very good" and (30.5\%) were neutral and medium answers in relation to the time taken to answer their questions.

Since the process of searching for sources is based on the quality of the search engines, the users indicated that the search process that relies on those engines is a rate of $(58.6 \%)$ and is considered an approximate percentage of the results of the first question, which indicated an estimated rate of (70\%) in terms of "the ability to search on the sources through the use of the library website".

Since the need has become urgent to use the Internet in all areas of life, especially academia, to keep abreast of technological developments and all that relates to the academic environment, as we mentioned earlier to overcome the information gap, including digital in the academic field and facilitate searches for users, the results of the answer to the questionnaire by the users in The University of Jordan that the University is based on supporting the use of the Internet by providing a computer for each teacher and an internet connection that enables them to connect to the databases available in the library, and the ratio was average compared to the previous questions and other axes of the study, where it indicated (64.4\%) between "good and very good" and with an average rate that the university supports the use of the Internet only within the limits $(19.7 \%)$.

As for providing tools and facilities that help users to make optimal use of databases and their sources, the results indicate neutrality in answering this question, as the users from the library indicated that "there is a weakness in providing tools and facilities when using the university library site" at a rate of $(34.45 \%)$, with a frequency of 70 and a standard deviation of (3.23).

\subsection{Informational Content}

The information content of any website plays the pulsating role of the life of traditional and digital libraries. In this study, several axes were discussed aiming at the extent of the users' satisfaction with covering the website of the library and its information content that helps the users to benefit from it and put it in the service and development of scientific research. 
Table No. (11) Quality and availability of contents

\begin{tabular}{|c|c|c|c|c|c|c|}
\hline Questions & $\begin{array}{l}\text { Very } \\
\text { Good }\end{array}$ & Good & Medium & Bad & $\begin{array}{l}\text { Very } \\
\text { Bad }\end{array}$ & $\begin{array}{l}\text { Standard } \\
\text { Deviation }\end{array}$ \\
\hline $\begin{array}{l}\text { 1. How would you rate the format (PDF, } \\
\text { HTML) of information retrieval? }\end{array}$ & $\begin{array}{c}71 \\
35.0 \%\end{array}$ & $\begin{array}{c}73 \\
36.0 \%\end{array}$ & $\begin{array}{c}44 \\
21.7 \%\end{array}$ & $\begin{array}{c}9 \\
4.4 \%\end{array}$ & $\begin{array}{c}4 \\
2.0 \%\end{array}$ & 3,98 \\
\hline $\begin{array}{l}\text { 2. How would you rate information coverage for } \\
\text { your scientific and research areas of interest? }\end{array}$ & $\begin{array}{c}61 \\
30.0 \%\end{array}$ & $\begin{array}{c}86 \\
42.4 \% \\
\end{array}$ & $\begin{array}{c}10 \\
19.7 \%\end{array}$ & $\begin{array}{c}14 \\
9.6 \%\end{array}$ & $\begin{array}{c}2 \\
11.0 \%\end{array}$ & 3,93 \\
\hline $\begin{array}{l}\text { 3. How do you consider the quality of the } \\
\text { content, knowing that it comes from academic } \\
\text { and court sources? }\end{array}$ & $\begin{array}{c}63 \\
31.0 \%\end{array}$ & $\begin{array}{c}74 \\
36.5 \%\end{array}$ & $\begin{array}{c}52 \\
25.6 \%\end{array}$ & $\begin{array}{c}11 \\
5.4 \%\end{array}$ & $\begin{array}{c}3 \\
1.5 \%\end{array}$ & 3,90 \\
\hline $\begin{array}{l}\text { 4. The sources of information provided by the } \\
\text { electronic library with high quality? }\end{array}$ & $\begin{array}{c}67 \\
33.0 \% \\
\end{array}$ & $\begin{array}{c}65 \\
32.0 \%\end{array}$ & $\begin{array}{c}46 \\
22.7 \%\end{array}$ & $\begin{array}{c}17 \\
8.4 \% \\
\end{array}$ & $\begin{array}{c}8 \\
3.9 \%\end{array}$ & 3,81 \\
\hline
\end{tabular}

The results and data mentioned in Table No. (11) indicate that the users evaluate the coordination of the full texts of the articles retrieved from the HTML and PDF as a higher level of good, as the ratio was (71\%) and with repetition of 144 out of 203 of the total study sample. The negative percentage (that is, dissatisfaction) does not exceed $(6.5 \%)$ of the total, and the standard deviation (3.98). Also, here the following question also supports the previous users' answer and agrees with it at a rate of (72\%) that the objective coverage of the fields of scientific and research interests of the users and its standard deviation (3.93). In addition, the response rate to the quality of information in terms of arbitration and the reliability of the information was $(71.5 \%)$ and the dissatisfaction rate did not exceed (7\%). This supports and corresponds to the answers that expressed that there is a high quality of information provided by the library at a rate of (75\%) and the frequency of 132 out of 203 of the total for the study sample.

The results of the mathematical circles of the paragraphs of the second part about the site design and search engines at the University of Jordan's digital library showed that it is high, and this indicates that the pioneers of the electronic library at the University of Jordan has a satisfaction with the site design and it is highly appropriate as well as search engines and the total medium for these paragraphs is (3.73) which is a high score.

As for the third part related to the contents in the electronic library, the answers were also high, and the total arithmetic mean has reached (3.9), and this greatly confirms that the contents of the electronic library achieve great satisfaction among the research students where there are no less than (50) global website linked with the University of Jordan that provides many scientific studies for students.

\section{Study hypotheses test}

The first hypothesis

Nihilistic hypothesis: Site design and search engines in the digital library at the University of Jordan do not achieve proper information acquisition.

Alternative hypothesis: Site design and search engines in the digital library at the University of Jordan achieve access to appropriate information.

Table No. (12) rejecting or accepting the nihilistic or alternative hypothesis to test the first hypothesis

\begin{tabular}{|c|c|c|c|}
\hline Calculated T & Tabular T & Level of significance & Reject or accept the hypothesis \\
\hline 14.60 & 1.68 & 0.00 & Rejection of the nihilistic hypothesis \\
\hline
\end{tabular}

The results of the One Sample T-test showed that the calculated value of $(\mathrm{T})$ is greater than the tabular $(\mathrm{T})$ with a significance level of 0.00 less than 0.05 and this indicates the rejection of the nihilistic hypothesis and the acceptance of the alternative hypothesis, that is, the site design and search engines in the digital library at the University of Jordan achieve obtaining information in the appropriate way as there are many subscriptions through the electronic library at the University of Jordan with many international and research journals, and this result confirms that the study sample benefits greatly from the digital library.

The second hypothesis

Nihilistic hypothesis: The contents of the digital library at the University of Jordan do not meet the full satisfaction of the user.

Alternative hypothesis: The contents of the digital library at the University of Jordan meet the full satisfaction of the user.

Table No. (13) rejecting or accepting the nihilistic or alternative hypothesis to test the second hypothesis

\begin{tabular}{|c|c|c|c|}
\hline Calculated T & Tabular T & Level of significance & Reject or accept the hypothesis \\
\hline 17.76 & 1.68 & 0.00 & Rejection of the nihilistic hypothesis \\
\hline
\end{tabular}

The results of the One Sample T-test indicate that the calculated value of $(\mathrm{T})$ is greater than the tabular (T) with a significance level of 0.00 less than 0.05 and this indicates the rejection of the nihilistic hypothesis and the acceptance of the alternative hypothesis, meaning that the contents of the digital library at the University of Jordan meet the full satisfaction of the user where there is a lot of content in the digital library encouraging students and 
researchers to access more than one magazine and more than a site of research published internationally. Through the digital library, many universities can be contacted, and all master's and doctoral theses can be seen from A to $Z$. This is one of the factors that helped the Jordan Digital University library to be the intended destination not for students studying in Jordanian universities, but there are many students who come from outside Jordan.

\section{Results and Recommendations}

A critical step for QFD practitioners in assessing digital libraries is to define users' requirements (and what). To study the case presented in this paper, a broad literature review on the quality of services for digital libraries is defined and displayed on pink in Figure 5.

The results helped to see how each group categorized the importance of knowing what it was. Corresponds to greater importance, less coverage and search engines respectively (see relevance for what is, Figure 5).

Technical requirements, how they were determined according to current library operations (main activities). These are highlighted in green in the figure. 5. By focusing on such (how), we guarantee to the users that they will get the quality of service. Relationships between what and how were established by the expert group, which consisted of authors and two directors from the digital library. These numbers can be seen in the red part of the figure. 5. The highest importance of achieving How was for the budget, followed by site ranking and site design. These requirements indicate the specific activities that should be improved to achieve the greatest impact on user satisfaction. At this point, the classic analysis of the quality house is completed.

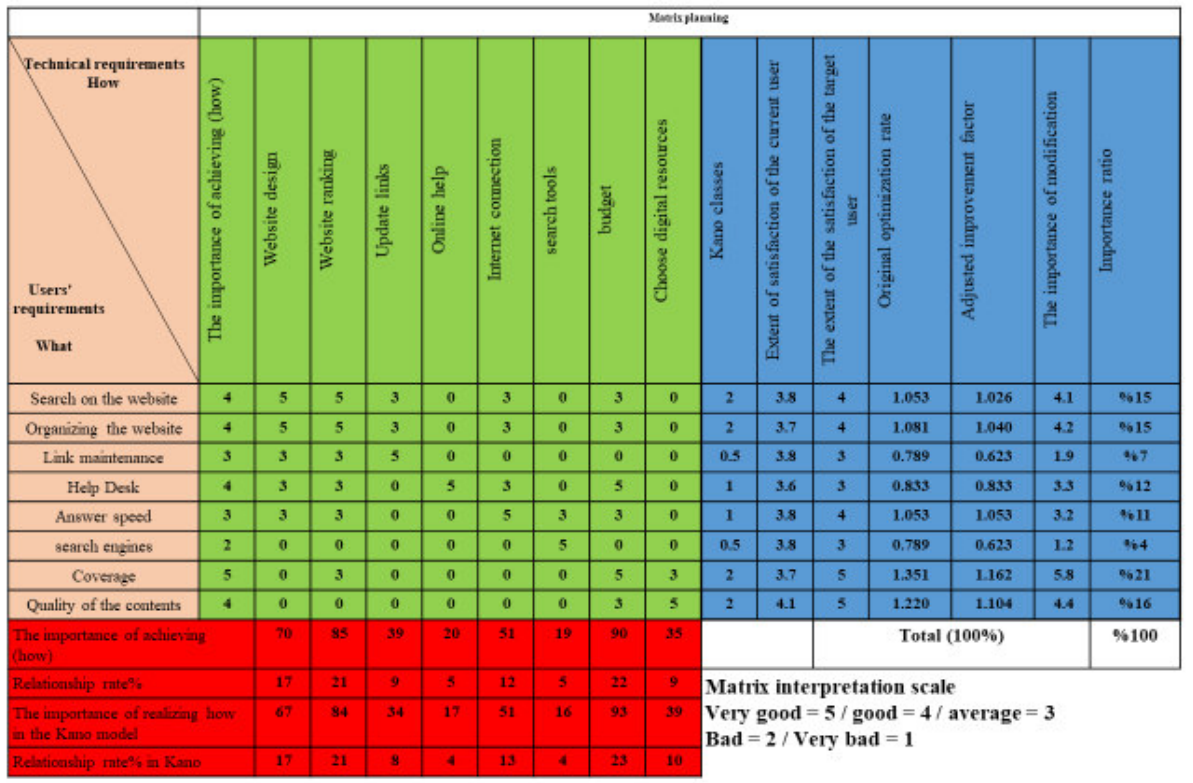

Figure No. (5) Kano Model and Quality Deployment Function Model at the University of Jordan Library

\section{The results of the field study showed the following:}

The aim of the Kano Model is to re-prioritize the requirements of the users in order to obtain an order to present the priorities that should identify and address the needs of the user from the digital library first. The views of the expert group were on setting these priorities. Figure No. (5) shows the changes in the quality deployment function presented in blue according to the categories in Kano, which are listed in the first column. The results were attractive - four (2), two are one-dimensional (1), and two must have attributes (0.5).

In the second column, it can be seen how the users view the current service of the Jordan University Digital Library. These numbers correspond to the average values for the 203 questionnaires identified and reported in the tables data in the section on analyzing and discussing the questionnaire.

The third column indicates the satisfaction of the intended users, such as giving priority to the Kano categories, and a team of experts has defined these values. Thus, the original improvement ratio (IR0) is indicated in the fourth column. Values were calculated as shown in the methodology section. The results recorded five (IR0) values greater than 1, which are good indicators of poor operations that users' requirements indicated that they should receive priority attention in order to improve this process. Users' requirements should be considered with the highest value in the first and lowest in the last. In this study, the three highest requirements for users, objective coverage (1.351), quality of content $(1.220)$, and site organization $(1,081)$ should be the primary concern of the library. However, response speed and site research both have the same value of 1,053 . As such, all of these optimization factors are considered raw or new and have not yet been expressed in the formula of (Shen and Tan's) which is $(\operatorname{IRadj}=($ IR0 $) 1 / \mathrm{k})$. Just previously noted, tuning optimization factors for all users' requirements in the 
Kano category. The IRadj setting appears in the fifth column.

Although the improvement factors were set greater than referring to a user requirement that should be improved, there is no information regarding the users' requirements that should take the priority in the introduction as presented in the figures. Therefore, it was necessary to calculate the importance rate by multiplying the (IRadj) times the importance of "what" is (the first column in green) to provide a more clear view of what the first users 'requirements should be addressed in the sixth column and converting the importance adjustment in a percentage as shown in the last column. In this column, the requirements of the users with the highest percentage of coverage $(21 \%)$, followed by the quality of the content $(16 \%)$, both search in the site and site organization with the same value of $15 \%$. These clearly indicated values should address the needs of the user primarily in order to improve the quality of services provided by digital university libraries.

In order to find out which of the technical requirements (how) are most important to the digital library project, the "What" column is replaced by an importance rate column that takes into account the Kano classes, and according to the QFD methodology, the importance of (how) in (Kano) was calculated. For example, a new importance for site design is 67 , because $(4.1 \times 5+4.2 \times 5+1.9 \times 3+3.3 \times 3+3.2 \times 3+1.2 \times 0+5.8 \times 0+4.4 \times$ $0=67$ ) and the percentage for website design $67 / 401$ or $17 \%$. Results appear in the last two rows that are shown in yellow in figure 5, pointing out that the most important technical requirements are budget (23\%), followed by ranking sites $(21 \%)$. It is also worth noting that the importance of "how" in "kano", and the importance of "how" without the kano methodology display the same current values (first and third yellow rows, respectively). This is because the satisfaction of the users obtained was good for the survey as can be seen in Table 1. Based on the voice of the user, which is the basis of the digital library and as it is in the form of an online questionnaire, the emphasis on the importance of (how) in (Kano) indicates the existence of the system In specific activities required to improve and develop the digital library.

1- The results of the arithmetic test results of the study paragraphs on website design and search engines showed that these media are highly rated, and this indicates that the design was well evaluated by the library users.

2- The results of the mathematical circles for the questionnaire paragraphs about the contents of the electronic library indicated that these circles are high and stated that the contents of the library meet the needs of the users of the library.

3- The results of the first hypothesis test confirmed that the site design and search engines in the digital library at the University of Jordan achieve obtaining information in an appropriate manner.

4- The results of the second hypothesis indicated that the contents of the digital library at the University of Jordan meet the full satisfaction of the users.

Considering the above results, the study recommends the following:

1- The need for private Jordanian universities to link with the libraries of public universities.

2- The necessity of increasing participation in digital databases to overcome the information gap between Jordan and developed countries.

3- The necessity of developing databases in the electronic library to cover all important topics in the field of scientific research, which is reflected in bridging the gap in this field.

4- Conducting other studies to evaluate the private university libraries.

5- Emphasizing the role of academic libraries in providing users with training programs and workshops.

\section{References}

1. Abdullah, F. (2006). Measuring service quality in higher education: HEdPERF versus SERVPERF. Marketing Intelligence and Planning, 24 (1), PP. 31-47. https://doi.org/10.1108/02634500610641543.

2. Abdullah, F. (2009). HEdPERF versus SERVPERF: The quest for ideal measuring instrument of service quality in higher education sector. Quality Assurance in Education, 13 (4), PP. 305-328. https://doi.org/10.1108/09684880510626584.

3. Banwell, Linda; Ray, Kathryn; Coulson, Graham; Urquhart, Christine; Lonsdale, Ray; Armstrong, Chris; Thomas, Rhian; et al. (2004). The JISC user behavior monitoring and evaluation framework. Journal of Documentation, 60 (3). pp. 302-320. ISSN 1758-7379.

4. Beck, Susan (May 5, 2005). Evaluation criteria. The good, the bad and the ugly: or why it's a good idea to evaluate web sources. from: http://lib. nmsu.edu/instruction/evalcrit.html

5. Behnert, Christiane; Lewandowski, Dirk (2017). A framework for designing retrieval effectiveness studies of library information systems using human relevance assessments, Journal of Documentation, 73 (3). doi: 10.1108/JD-08-2016-0099.

6. Breeding, M. (2002). Strategies for measuring and implementing E-use, Library Technology Reports. 38 (3), p. 1.

7. Briggs, Asa and Burke, Peter (2002). A Social History of the Media: From Gutenberg to the Internet, Polity, Cambridge, pp.15-23, 61-73. 
8. Cochran, David \& Eversheim, Walter \& Kubin, Gerd \& Sesterhenn, Marc. (2000). The Application of Axiomatic Design and Lean Management Principles in the Scope of Production System Segmentation. The International Journal of Production Research. 38. pp. 1377-1396. 10.1080/002075400188906.

9. Cullen, R. (2001). Perspectives on user satisfaction surveys, Library Trends. 49 (4), pp. 662-686.

10. Eke, Helen Nneka; Omekwu, Charles Obiora; and Agbo, Juliet (2014). Internet Search Strategies Employed by Library and Information Science Students of University of Nigeria, For Research. Library Philosophy and Practice (e-journal). 1194. From: http://digitalcommons.unl.edu/libphilprac/1194

11. Gates, B. (1995). The road ahead (Ed. Viking Penguin, EUA. 1995).

12. Heradio, Ruben \& Fernandez-Amoros, David \& Cabrerizo, Francisco \& Herrera-Viezma, Enrique. (2012). A review of quality evaluation of digital libraries based on users' perceptions. Journal of Information Science. 38. pp. 269-283. 10.1177/0165551512438359.

13. Houghton, J. (2004). Research practices, evaluation and infrastructure in the digital environment, Australian Academic and Research Libraries, 35 (3), pp. 161-176.

14. Holm-Nielsen, L. B. (2001, August 15). Challenges for the higher education systems. Paper presented at HE$\mathrm{R}$ 2001, International Conference on Higher Education Reform, Jakarta. from : http://www.usp.ac.fj/worldbank2009/frame/Documents/Publications_global/Challenges_for_higher_ed_syst emsEn01.pdf

15. International Labour Organization (2012). International Standard Classification of Occupations 08: Structure, Group Definitions and Correspondence Tables. Geneva, From: https:/www.ilo.org/wcmsp5/groups/public/--dgreports/---dcomm/publ/documents/publication/wcms_172572.pdf

16. Kani-Zabihi, E., Ghinea, G. and Chen, S.Y. (2006), Digital libraries: what do users want?. Online Information Review, 30 (4), pp. 395-412.

17. Kano, N., Seraku, N., Takahashi, F. and Tsuji, S. (1984). Attractive Quality and Must-Be Quality. Journal of the Japanese Society for Quality Control, 41, pp. 39-48.

18. MacCall (2006). Clinical digital libraries project: design approach and exploratory assessment of timely use in clinical environments, Journal of the Medical Library Association. 94 (2), pp. 190-198.

19. Matzler, K. and Hinterhuber, H. (1998). How to Make Product Development Projects More Successful by Integrating Kano's Model of Customer Satisfaction into Quality Function Deployment. Technovation, 18, pp. 25-38.

20. Office of Educational Technology (2017). Reimagining the Role of Technology in Education: 2017 National Education Technology Plan Update. U.S. Department of Education. From: https://tech.ed.gov/files/2017/01/NETP17.pdf

21. Priyono, Anjar \& Yulita, Andina. (2017). Improving service quality of hospital front office using an integrated Kano model and quality function deployment. Intangible Capital. 13. 924. 10.3926/ic.1001.

22. Saarti, J. (2006). Libraries without walls: information technology in finish public libraries from the $1970 \mathrm{~s}$ to the 1990s, Library History, 22 (1), pp. 33-43.

23. Schryer, S. (2006). 'Real simple? Exploring online user satisfaction in Michigan', Library Journal, 131 (18), pp.34-36.

24. Schwab, Klaus (2016). The Fourth Industrial Revolution: what it means, how to respond. World Economic Forum, Global Agenda. From: https://www.weforum.org/agenda/2016/01/the-fourth-industrial-revolutionwhat-it-means-and-how-to-respond/

25. Sharma, R.K. and Vishwanathan, K.R. (2001). Digital libraries: development and challenges, Library Review. $50(1)$, pp. 10-16.

26. Tan, K. C. \& Shen, X. X. (2000). Integrating Kano's model in the planning matrix of quality function deployment, Total Quality Management, 11 (8), 1141-1151. DOI: 10.1080/095441200440395.

27. Tan, K.C., \& Pawitra, T.A. (2001). Integrating SERVQUAL and Kano's model into QFD for service excellence development. Managing Service Quality: An International Journal, 11 (6), 418-430. https://doi.org/10.1108/EUM0000000006520

28. Tonta, Yaşar (2004). Electronic Information Management. Research and Technology Organization. From: https://www.academia.edu/255624/Electronic_Information_Management_Edited_by_Ya\%C5\%9Far_Tonta

29. Uppalanchi, Anusha (2010). Application of Quality Function Deployment in new product and service development. Masters Theses. 6939. From: https://scholarsmine.mst.edu/masters theses/6939

30. van den Hoven, Jeroen; Blaauw, Martijn; Pieters, Wolter; and Warnier, Martijn (2019). Privacy and Information Technology. The Stanford Encyclopedia of Philosophy. Metaphysics Research Lab, Stanford University. From: https://plato.stanford.edu/archives/win2019/entries/it-privacy/

31. van Iwaarden, J., \& van der Wiele, T. (2003). Applying SERVQUAL to Websites: An exploratory study. International Journal of Quality \& Reliability Management, 20 (3), pp. 919-935. From: https://doi.org/10.1108/02656710310493634. 
32. Wang, Z. (2003). The digital library quality, SCI/TECH Information Development and Economy. 13 (1), pp. 32-34.

33. Xia, W. (2003). Digital library services: perceptions and expectations of user communities and librarians in a New Zealand academic library, Australian academic and research libraries. 34 (1), pp. 56-70.

34. Zhou, Q. (2005). The development of digital libraries in China and the shaping of digital libraries in China and the shaping of digital librarians, The Electronic Library. 23 (4), pp. 433-442.

\section{About the author}

Othman Abdulkader Obeidat, Head of Library and Information Management Department. And teaches with the Faculty of Al-Salt for Humanity Sciences at Al-Balqa' Applied University in Jordan. He has published on various subjects related to academic and digital libraries, with a focus on digital divide. Othman Obeidat is the corresponding author and can be contact on: 